\title{
CD4 T Cell Count in Newly diagnosed PTB Patients With Reference to their HIV Sero status
}

\author{
Piyush Rajbhandari', Nimesh Poudyal', Rajendra Gurung ${ }^{2}$, Bikram Pradhan ${ }^{2}$ and SK \\ Bhattacharya $^{2}$,
}

${ }^{1}$ Patan Academy of Health Sciences, Lalitpur, Nepal. ${ }^{2}$ BP. Koirala Institute of Health Sciences, Dharan, Nepal.

\section{ABSTRACT}

Introduction: CD4 and CD8 T cells facilitate the containment of tuberculosis (TB) and has been postulated that there will be changes in their level in patients with TB. This study was carried out to analyze the CD4 cell counts in pulmonary tuberculosis (PTB) patients with reference to their HIV status.

Methods: A cross-sectional study was conducted at the Department of Microbiology of a tertiary care hospital of eastern Nepal from May 2012 to April 2013. A total of 160 individuals, 40 each in the PTB, PTB/HIV, HIV and healthy population were included after obtaining informed consent. PTB and HIV diagnosis was made according to national guidelines. CD4 T cells were analyzed using a BD FACS Count Cytometer. Data were entered in Microsoft Excel 2007 and analyzed using SPSS version 11.7.

Results: The mean absolute CD4 cells in PTB patient were $562.20 \pm 197.3$ cells/ul, which was a clear reduction $(p<0.001)$ when compared to the healthy population of this area $(786.30 \pm$ 239.17 cells/ul). There was significant decrease in the CD4 level among the HIV/TB patient $(123.70 \pm 99.4$ cells/ul $)$ as compared to PTB patient without HIV $(\mathrm{p}<0.001)$. The study also noted that the mean CD4 cell level among HIV infected population (249.68 cells/ul) was higher compared to the HIV/TB co-infected population $(\mathrm{p}<0.05)$.

Conclusion: CD4 cell count can reflect the degree of immunosuppression in PTB patient irrespective of their HIV status but it cannot predict the disease severity in PTB patient.

Key words: CD4 cells; pulmonary tuberculosis; HIV

\section{INTRODUCTION}

Cell mediated immunity plays an important role in eliminating mycobacterium. In advanced disseminated $\mathrm{TB}$, numbers of circulating $\mathrm{T}$ lymphocytes, especially CD4 cells are reduced while number of CD8 cell are increased. ${ }^{1}$ The CD4 cell appear to exert their immunological effect through cytotoxicity against infected target cells partly by production of INF- $\gamma$ and also by intern activation of the mycobacterium infected macrophages which then kills the bacilli. ${ }^{2}$

The reduction of CD4 cell is believed to be a result of homing of these subsets in the lungs. This shift is related to the severity of pulmonary involvement and is inversely

Correspondence: Piyush Rajbhandari, Patan Academy of Health Sciences, Lalitpur, Nepal. Email: piyushrajbhandari@pahs.edu.np 
related to the CD8 cells in the peripheral blood and bronchoalveolar lavage fluid. ${ }^{3}$

This proposed study aims at evaluating and understand the change of CD4 T lymphocyte cell count in PTB patient with and without HIV presenting at one of the tertiary care hospital of eastern Nepal.

\section{METHODS}

This was a hospital based comparative crosssectional study conducted from May 2012 to April 2013 in one of the tertiary care hospital of eastern Nepal. The study population consisted of four groups of newly diagnosed PTB patient without HIV; HIV/TB co-infected patient; newly diagnosed HIV patient without TB and Healthy adults for reference values. The total HIV/TB co-infected patients diagnosed in the hospital over the period of one year were taken into account and equal number to each group was allocated accordingly. Total $40 \mathrm{HIV} / \mathrm{TB}$ co-infected patients were diagnosed over the study period; hence, the total number of individuals in the study was 160 , each group with 40 individuals.

All the sputum negative or extra-pulmonary TB along with defaulter, relapse or re-infected cases were excluded from this study. Patient with immune compromised state other than HIV or who were already under treatment for TB or HIV were also excluded.

Smear positive PTB was diagnosed according to National Guidelines being at least two out of three sputum samples showing acid-fast bacilli by Ziehl Neelsen (ZN) staining. ${ }^{4}$ All newly diagnosed PTB patients during the study period were counseled about the study and HIV counseling and testing was done for those who gave written consent. Those who consented were asked for blood sample in ethylene diamine-tetra-acetic acid (EDTA) tubes. The same sample was used for HIV test and for CD4 T cell counts.

Newly diagnosed HIV patient attending the VCT clinic and CD4 Laboratory were counseled about the study. Those who consented were asked to give sputum samples, which were sent to the TB laboratory for smear microscopy. Sputum sample was obtained from each patient according to NTP guideline. ${ }^{4}$ Tuberculosis diagnosis was made based on the finding of AFB by fluorescence microscopy followed by Ziehl Neelsen (ZN) staining. Blood was collected in ethylene (EDTA) tubes for CD4 T cell counts.

Students undergoing medical checkup in the GOPD for taking admission in the 2012 postgraduate program in the hospital and staff were counseled about the study and those who were medically fit, HIV negative, without TB and any other immune modulating conditions were included in the study. Individuals were interviewed, using a structured questionnaire, and screened for symptoms such as fever, cough and weight loss to rule out any recent and/or current infections. Blood was collected in EDTA tubes of individuals giving written consent for CD4 $\mathrm{T}$ cell counts measurement.

Completed questionnaires were coded by numbers and double entered in computer software, Microsoft Office Excel 2007. The data was then transferred to Statistical Package for Social Sciences version 11.5 (SPSS Inc, Chicago, USA) for analysis. Student $t$ test was used to test for differences in mean between two groups and ANOVA was used to compare mean of more than two groups. Descriptive analysis was done to find the mean between different groups and standard deviation. All 
Table 1: CD4 and CD8 $\mathrm{T}$ cell count in different study population. PTB: Pulmonary tuberculosis, HIV: Human immunodeficiency virus.

\begin{tabular}{|l|l|l|}
\hline Group & CD4 $($ cells/ $\boldsymbol{\mu l})$ & CD8 $($ cells/ $\boldsymbol{\mu l})$ \\
\hline Healthy & $786.3 \pm 239.2$ & $496.78 \pm 218.23$ \\
\hline PTB & $562.20 \pm 197.33$ & $455.38 \pm 244.07$ \\
\hline HIV & $331.40 \pm 173.64$ & $898.75 \pm 393.69$ \\
\hline HIV/TB & $123.7 \pm 99.44$ & $665.43 \pm 483.88$ \\
\hline
\end{tabular}

statistical tests were considered significant if the two sided P-value (p) was $<0.05$.

\section{RESULTS}

A total of 160 individuals were enrolled during the study period. Among them 58.1\% were male, $41.3 \%$ were female and $0.6 \%$ were third gender. The mean age among them was 35.82 years.

The mean absolute CD4 $\mathrm{T}$ cell in healthy population was found to be $786.3 \pm 239.2$ cells/ $\mu 1$ while CD8 cells were $496.78 \pm 218.23$ cells/ $\mu 1$ and $\mathrm{CD} 4 / \mathrm{CD} 8$ ratio was 1.8 . No significant variation in the mean absolute CD4 and CD8 T-lymphocyte counts was found between the male and female of this group. Among the 40 primary PTB patients who were HIV seronegative, the mean absolute CD4, CD8 and CD3 $\mathrm{T}$ cell were found to be 562.20 cells $/ \mu$, $455.38 \mathrm{ce} 11 \mathrm{~s} / \mu 1$ and $1063.98 \mathrm{cells} / \mu 1$ respectively. The $\mathrm{CD} 4 / \mathrm{CD} 8$ ratio was 1.39 . In case of the newly diagnosed HIV infected patient it was found that the mean absolute CD4 T cell was $331.40 \pm 173.64$ cells $/ \mu 1$. The CD4 cells were as low as 13 cells $/ \mu 1$, while the maximum level was 744 cells/ $\mu 1$. Regarding the HIV/TB co-infected patient, the mean absolute CD4 T Lymphocyte was 123.7 cells/ $\mu 1$ with a minimum of 5 cells $/ \mu 1$ and maximum of 451 cells $/ \mu 1$ (Table 1$)$.

When the mean CD4 T lymphocyte was compared between the PTB patients against the healthy reference population, it was found that the mean CD4 $\mathrm{T}$ lymphocyte count was 224.1 cells $/ \mu \mathrm{L}$ lower among PTB patients. This was significantly lower than the reference value for this population $(p<0.001)$. The CD4 count was 230.8 cells $/ \mu \mathrm{L}$ higher among PTB patients when compared with the HIV patient without PTB. It was significantly higher than the CD4 cell level in HIV patient $(p<0.001)$. In case of PTB patient the mean absolute CD4

Table 2: Comparison of CD and CD8 T cell count in different study population

\begin{tabular}{|c|c|c|c|c|c|c|}
\hline \multicolumn{2}{|r|}{ Status } & Mean & Std. Deviation & Mean Difference & $\begin{array}{l}\text { Std. Error } \\
\text { Difference }\end{array}$ & Sig (P value) \\
\hline \multirow[t]{4}{*}{ CD4 } & PTB & 562.20 & 197.336 & & & \\
\hline & Normal & 786.30 & 239.171 & -224.100 & 49.027 & $<0.001$ \\
\hline & HIV & 331.40 & 173.644 & 230.800 & 41.561 & $<0.001$ \\
\hline & HIV/PTB & 123.70 & 99.447 & 438.500 & 34.940 & $<0.001$ \\
\hline \multirow[t]{4}{*}{ CD8 } & PTB & 455.38 & 244.078 & & & \\
\hline & Normal & 496.78 & 218.232 & -41.400 & 51.769 & 0.426 \\
\hline & HIV & 898.75 & 393.693 & -443.375 & 73.241 & $<0.001$ \\
\hline & HIV/PTB & 665.43 & 483.882 & -210.050 & 85.691 & $<0.05$ \\
\hline
\end{tabular}


cell level was found to be $562.20 \pm 197.37$ while 123.7 \pm 99.44 in case of the HIV/TB co-infected patient. Thus, the CD4 count was significantly higher among PTB patients than in HIV/TB co-infected group $(\mathrm{p}<0.001)$.

\section{DISCUSSION}

Tuberculosis remains one of the major global health problems with almost 9 million new cases and 1.4 million TB deaths in 2011. About one-third of the world's population has latent TB of which $10 \%$ has a life time risk of falling ill with TB. ${ }^{5}$ This risk of acquiring active disease once infected is determined by the degree of malnutrition, renal failure and immunosupression while protective immunity to tuberculosis in humans depends upon both CD4 and CD8 T lymphocytes. ${ }^{6}$ These cells facilitate the containment of infection and has been postulated that there will be changes in the immunophenotypic characterization of the $\mathrm{T}$ lymphocytes and their subpopulations in patients with active TB. 7 This study was undertaken to determine the changes and to compare the mean and absolute numbers of peripheral $\mathrm{T}$ lymphocytes in adult newly diagnosed PTB patient with respect to their HIV sero-status and to find out the relationship between CD4 cells and severity of PTB if any.

Our healthy population, comprised of adult Nepalese of mixed gender and ethnicity, had mean absolute lymphocytes subpopulations comparable to the values reported from Chinese population ( 730 cells $/ \mu \mathrm{L})$ and the values reported from a few African countries such as Tanzania (median 723 cells/ $\mu \mathrm{L}$ ) and Botswana (median 726 cells $/ \mu \mathrm{L}$ ) ${ }^{8-10}$. The values obtained in present study were lower than the absolute CD4+ T cell counts reported from Indian population (919 cells $/ \mu \mathrm{L})$, Caucasian populations (1036 cells $/ \mu \mathrm{L})$, British
(830 cells/ $\mu \mathrm{L}$ ), Dutch populations (993 cells/ $\mu \mathrm{L})$, Thai population $(910 \pm 310$ cells $/ \mu \mathrm{L})$ and population from Nigeria $(861$ cells $/ \mu \mathrm{L})$. 11-17 This variation in CD4 $\mathrm{T}$ cell count has been shown to be influenced by sex, age, race, time of specimen collection (diurnal rhythms), physical and psychological stress. Apart from physiologic or pathologic conditions, factors that cause variations in the CD4 T cell counts also include instrument used, time of collection and methodologies used for collection, processing and analyzing the whole blood samples. The factors such as integrity of the blood sample, staining reagents and fluorochromes, equipment calibration and performance, gating strategies used for the analysis also add to the variation in the CD4+ $\mathrm{T}$ cell counts. Strict adherence to standardized procedures and guidelines can help to reduce the variation. ${ }^{18-21}$ Although the sample taken in this study is only 40 , the CD4 $\mathrm{T}$ lymphocytes subset count in Nepalese population is lower compared to the Western and European population. This finding is consistent with the finding of Shakya G. et al. ${ }^{22}$

This study shows a clear reduction in the mean absolute numbers of CD3 $(\mathrm{p}<0.01)$ and CD4 $(p<0.001)$ in patients with pulmonary TB compared to the healthy population at this area but there is no significant difference in the CD8 T lymphocytes $(p=0.426)$. Study conducted in 2008 by FM Al Majid also found the significant reduction in CD4 and CD3 lymphocytes but no significant changes were seen in the CD8 cell values which are consistent with the finding of this study. ${ }^{7}$ This reduction in CD4 and CD3 cell level has also been noted in the works of other researchers like Singhal M. et al, Onwubalili JK et al and Swaminathan S. et al. 2, 23, 24 Our study could 
not find any variation in mean CD8 level among the primary PTB group.

This significant variation in the CD4 lymphocytes in PTB patient is thought to be relative rather than absolute decrease. This is suggested by the rise in CD4 cell level after initiation of anti-tuberculosis therapy. ${ }^{1}$ This fall in the CD4 cell level is thought to be due to pooling or homing of these cells from peripheral circulation to the infected area, lungs in this case. This phenomenon of homing or pooling of CD4 cells has been described by Mercedes Gonzalez-Juarrero et al in their study of temporal and spatial arrangement of lymphocytes within lung granulomas induced by aerosol infection with Mycobacterium tuberculosis. ${ }^{25}$ Tsao et al. have shown that this shift is related to the severity of pulmonary TB and is inversely related to the CD8 in the peripheral blood and bronchoalveolar lavage fluid. $^{26}$

The mean absolute CD4, CD8, CD3cells and CD4/CD8 ratio among the HIV/TB co-infected individuals were evaluated prior to initiation of both ART and ATT. There was significant decrease in the CD4 level among the HIV/TB co-infected study group as compared to PTB patient without HIV $(\mathrm{p}<0.001)$. The study also noted that the mean CD4 cell level among HIV infected population was higher compared to the HIV/TB co-infected population $(p<0.05)$. It is widely accepted that the number of circulating CD4+ $\mathrm{T}$ cells can be used as a measure of global "immune competence" and a predictor of the immediate risk for opportunistic illnesses. This significant fall in CD4 level in HIV/TB co-infected population can be attributed to the findings that in individuals with latent Mycobacterium tuberculosis infection, CD4 depletion accelerates the progression from latent infection to active tuberculosis, which, in turn, is believed to further fuel HIV replication rates due to elevated levels of pro-inflammatory cytokines. 27 TB by itself has also been associated with transitory lymphopenia including the CD4 positive cell lines. ${ }^{1}$

Similar type of decrease in CD4 cell level among HIV/TB co-infected population compared to active TB has been reported in the studies conducted by Denise do Socorro S. Rodrigues et. al (53.5 cells $/ \mu 1$ vs. 690 cells $/ \mu 1)$ and Martin DJ et al ( 230 cells/ $\mu 1$ vs. 630 cells/ $\mu 1) .{ }^{28,}{ }^{29}$ Similarly R A M Breen et al (119 cells $/ \mu \mathrm{l})$ and Fredy FC et al (40 cells $/ \mu \mathrm{l})$ have also reported the low CD4 level in HIV/TB coinfected patients. ${ }^{30,31}$ Some authors like Joseph $\mathrm{H}$ Perriens et al (316.5cells/ $\mu 1$ vs. 830.5 cells/ $\mu 1)$ and F. Mugusi et al (330 cells/ $\mu 1$ vs. 705 cells/ $\mu \mathrm{l}$ ) have reported CD4 level in HIV/TB patient to be higher in their studies compared to the HIV/TB population in this study. ${ }^{32,} 33$ This disparity could be due to the result of higher absolute CD4 level in their healthy population. However, the overall decrease in all the above mentioned studies showed statistically significant result.

This study showed that there is significant decrease in the CD4 cell level in PTB patient than the healthy population, which further decreases severely with HIV co-infection. Evaluation of CD4 cells were done prior to initiation of ATT in primary PTB patients but follow-up after ATT, sputum sample being negative or at the end of completion of therapy could not be done due to limited study period. Hence the level of CD4 cells at the end of therapy needs to be determined and it remains as a field of further study in the future. 


\section{CONCLUSION}

The CD4 cells count can be used as a tool to measure the degree of immunosuppression in PTB patient irrespective of their HIV status. Based on the observation made in the present study it is recommended that every PTB patient should be screened for HIV infection as the decreased CD4 level is more profound in HIV/TB co-infected patients.

\section{REFERENCES}

1. Jones BE OM, Taikwel EK, Qian D, Kumar A, Maslow ER, et al. CD4 cell counts in human immunodeficiency virus-negative patients with tuberculosis. . clin Infect Dis. 1997;24:988-91. DOI: http://dx.doi.org/ $\underline{10.1093 / \text { clinids/24.5.988 }}$

2. Singhal M BJ, Sharma S, Saha K. . Peripheral blood T lymphocyte subpopulations in patients with tuberculosis and the effect of chemotherapy. Tubercle. 1989;70:171-8. DOI: http://dx.doi.org/ $\underline{10.1016 / 0041-3879(89) 90047-0}$

3. Rodrigues DS ME, Wecks LY, Bonnez W, Salomao R, Kallas EG. Immunophenotypic Characterization of peripheral $\mathrm{T}$ lymphocytes in Mycobaterium tuberculosis infection and disease. Clin Exp Immunol. 2002;128:149-54. DOI: http://dx.doi.org/ 10.1046/j.1365-2249.2002.01809.x

4. Programme NT. A clinical manual for Nepal. Thimi, Bhaktapur: National Tuberculosis Centre; 2009.

5. WHO. Global Tuberculosis Report 2012. 2012 ed. Geneva2012. p. 82-5

6. Fitzgerald DW S T, Ha a D W. Mycobacterium tuberculosis. In: Mandell GL BJ, Dolin R, editor. Principle and practice of Infectious Diseases. 2. 7th ed: Churchill Livingstone; 2010. p. 3129-64. DOI: http://dx.doi.org/10.1016/ b978-0-443-06839-3.00250-2

7. FM Al Majid AA. Immunophenotypic characterisation of peripheral $\mathrm{T}$ lymphocytes in pulmonary tuberculosis.
J P G M . $2008 ; 54$ ( 1 ): 7 - 11. D O I : 10.4103/0022-3859.39182

8. Jiang W KL, Lu HZ, et al. Normal values for CD4 and CD8 lymphocyte subsets in healthy Chinese adults from Shanghai. Clin Diagn Lab Immunol 2004;11:811-3. DOI: http://dx.doi.org/10.1128/cdli. 11.4.811-813.2004

9. Ngowi BJ MS, Bruun JN, Morkve O. Immunohaematological reference values in human immunodeficiency virus-negative adolescent and adults in rural northern Tanzania. BMC Infect Dis. 2009;9(1). DOI: http://dx.doi.org/10.1186/1471-2334-9-1

10. Bussmann H WC, Masupu KV, Peter T, Gaolekwe SM, Kim S, et al. Low CD4+ Tlymphocyte values in human immunodeficiency virus-negative adults in Botswana. Clin Diagn Lab Immunol. 2004;11:930-5. DOI: http://dx.doi.org/ 10.1128/cdli.11.5.930-935.2004

11. Madhuri R Thakar PRA SA, Pachamuthu Balakrishnan, Bhaswati Bandyopadhyay, Ameeta A Joshi et al. Establishment of reference $\mathrm{CD} 4+\mathrm{T}$ cell values for adult Indian population. AIDS Research and Therapy. $\quad 2011 ; 8(35)$. D O I : 10.1186/1742-6405-8-35

12. Tollerud DJ CJ, Brown LM, Neuland CY, Pankiw-Trost LK, Blattner WA, et al. The influence of age, race, and gender on peripheral blood mononuclear-cell subsets in healthy nonsmokers. J Clin Immunol. 1989;9:214-22. DOI: http://dx.doi.org/ 10.1007/BF00916817

13. Royce RA WW, Jr. HIV infection, cigarette smoking and CD4+ T-lymphocyte counts: preliminary results from the San Francisco Men's Health Study. AIDS. 1990;4:327-33. D O I : h t t p : / / d x.d o i.org / 10.1097/00002030-199004000-00007

14. Bofill M JG, Lee CA, MacDonald-Burns D, Phillips AN, Sabin C, et al. Laboratory control values for CD4 and CD8 T lymphocytes. Implications for HIV-1 diagnosis. Clin Exp Immunol. 1992;88:243-52. DOI: http://dx.doi.org/ 10.1111/j.1365-2249.1992.tb03068.x 
15. Tsegaye A MT, Tilahun T, Hailu E, Sahlu T, Doorly $\mathrm{R}$, et al. Immunohematological reference ranges for adult Ethiopians. Clin Diagn Lab Immunol. 1999;6:410-4.

16. Vithayasai V ST, Sakonwasun C, Suvanpiyasiri C. Flow cytometric analysis of T-lymphocytes subsets in adult Thais. Asian Pac J Allergy Immunol. 1997;15:141-6.

17. Oladepo DK IE, Audu RA, et al. Establishment of reference values of CD4 and CD8 lymphocyte subsets in healthy Nigerian adults. Clin Vaccine Immunol. 2009;16:1374-7. DOI: http://dx.doi.org/ 10.1128/CVI.00378-08

18. Gelman R CS, Kidd P, Waxdal M, Kagan J. Assessment of the effects of instrumentation, monoclonal antibody, and fluorochrome on flow cytometric immunophenotyping: a report based on 2 years of the NIAID DAIDS flow cytometry quality assessment program. Clin Immunol Immunopathol. 1993;66:150-62. DOI: http://dx.doi.org/10.1006/clin.1993.1019

19. Giorgi JV CH, Margolick JB, Bauer KD, Ferbas J, Waxdal M, et al. Quality control in the flow cytometric measurement of $\mathrm{T}$ lymphocyte subsets: the multicenter AIDS cohort study experience. The Multicenter AIDS Cohort Study Group. Clin Immunol Immunopathol. 1990;55:173-86. DOI: h t t p : / / d x. d o i . o r g / $\underline{10.1016 / 0090-1229(90) 90096-9}$

20. Gratama JW KJ, Van den Beemd R, Hooibrink B, Van Bockstaele DR, Hooijkaas H. Analysis of variation in results of flow cytometric lymphocyte immunophenotyping in a multicenter study. Cytometry. 1997;30:166-77. DOI: http://

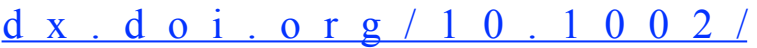
(SICI)1097-0320(19970815)30:4<166::AID -CYTO2>3.0.CO;2-I

21. Parker JW AB, Azen SP, Boone D, Fletcher MA, Gjerset GF, et al. Leukocyte immunophenotyping by flow cytometry in a multisite study: standardization, quality control, and normal values in the Transfusion Safety Study. The Transfusion
Safety Study Group. Clin Immunol Immunopathol. 1990;55:187-220. DOI: h t t p : / / d x . d o i . o r g / 10.1016/0090-1229(90)90097-A

22. Shakya G DS, Malla S, Sharma M, KC KP, Chhetri DB, Amatya R, Paudyal P. Values of Lymphocyte Subset in Nepalese Healthy Adult Population. J Nepal Med Assoc. 2012;52(185):6-13

23. Onwubalili JK EA, Palmer L. 1987;68:195-200. T4 lymphopenia in human tuberculosis. . Tubercle. 1987;68:195-200. DOI: http://dx.doi.org/ 10.1016/0041-3879(87)90055-9

24. Swaminathan S NK, Hanna LE, Somu N, Narayanan PR, Barnes PF. T-lymphocyte subpopulation in tuberculosis. Indian Pediatr. $2000 ; 375: 489-95$.DOI : $10.4103 / 0022-3859.39182$

25. Mercedes Gonzalez-Juarrero OCT, Joanne Turner, Peter Marietta, Jason V. Brooks, and Ian M. Orme. Temporal and Spatial Arrangement of Lymphocytes within Lung Granulomas Induced by Aerosol Infection with Mycobacterium tuberculosis infect immun. 2001;69(3):1722-28. DOI: 10.1128/ IAI.69.3.1722-1728.2001

26. Tsao TC CC, Hong JH, Hsieh MJ, Tsao $\mathrm{KC}$, Lee CH. Shifts of T4/T8 lymphocytes from BAL fluid and peripheral blood by clinical grade in patients with pulmonary tuberculosis.Chest. 2002;122:1285-91. DOI: http://dx.doi.org/10.1378/chest.122.4.1285

27. Ellner JJ. Immunoregulation in TB: observations and implications. Clin Transl Sci. 2010;3:23-8. DOI: http://dx.doi.org/ 10.1111/j.1752-8062.2010.00180.x

28. S Rodrigues Ddo S dCCR, Kallas EG, Salomao R. Distribution of naive and memory/effector CD4 + T lymphocytes and expression of $\mathrm{CD} 38$ on $\mathrm{CD} 8+\mathrm{T}$ lymphocytes in AIDS patients with tuberculosis. The Brazilian journal of infectious diseases : an official publication of the Brazilian Society of Infectious Diseases. 2003 Apr;7(2):161-5. DOI: http:// $\mathrm{d} x \cdot \mathrm{d} o \mathrm{i} \cdot \mathrm{org} / 10.1590 /$ $\underline{\text { S1413-86702003000200010 }}$ 
29. Martin DJ SJ, Sole GJ, Rymer L, Shalekoff $\mathrm{S}$, van Niekerk $\mathrm{AB}$, Becker P, Weilbach $\mathrm{CN}$, Iwanik J, Keddy K, et al. CD4+ lymphocyte count in African patients co-infected with HIV and tuberculosis. J Acquir Immune Defic Syndr Hum Retrovirol. 1995 April; 8(4):386-91. DOI: http://dx.doi.org/ 10.1097/00042560-199504000-00010

30. R A M Breen CJS, H Bettinson, S Dart, B Bannister, M A Johnson, M C I Lipman. Paradoxical reactions during tuberculosis treatment in patients with and without HIV co-infection Thorax. 2004;59:704-7.DOI: 10.1136/thx.2003.019224

31. Fredy FC LF, Kurniawan R, Nasir AU. The correlation between CD4+ T-lymphocyte count and tuberculosis form in TB-HIV coinfected patients in Indonesia. Acta Med Indones. 2012; 44(2) : 122-7.

32. Joseph H. Perriëns MDea. Pulmonary Tuberculosis in HIV-Infected Patients in Zaire - A Controlled Trial of Treatment for Either 6 or 12 Months. N Engl J Med 1995;332:779-85. DOI: http://dx.doi.org/ 10.1056/NEJM199503233321204

33. F. Mugusi EV, W. Urassa, E. Saathoff, R. J. Bosch, W. W. Fawzi. HIV co-infection, CD4 cell counts and clinical correlates of bacillary density in pulmonary tuberculosis. INT J TUBERC LUNG DIS 2006;10(6): $663-9$ 